\title{
Modern Trends in Business Management in the Light of Globalization
}

\author{
Andrea Cambalikova ${ }^{1, *}$ \\ ${ }^{1}$ University of Economics in Bratislava, Faculty of Business Management, Department of \\ Management, Dolnozemska cesta 1/b, 85235 Bratislava, Slovakia
}

\begin{abstract}
.
Research background: Under the influence of globalization and internationalization, corporations are emerging, and competition is taking on an international dimension. For companies, it is becoming necessary to adapt their traditional ways of doing business to the changed situation and new market opportunities, which results in the emergence of new management methods and tools. Research background is based on the results of international survey, which will serve us for the purpose of comparing the state of modern trends in management in the world and in Slovakia.

Purpose of the article: The main purpose of this article is to evaluate the application of modern trends in business management used by managers worldwide, as well as in enterprises in Slovakia, in terms of methods and tools by the implementation management functions and their impact on the enterprises.

Methods: The following scientific methods of research were used in the paper, namely analysis, synthesis, induction, deduction, comparison, and results of questionnaire surveys.

Findings \& Value added: The article is dedicated to the results of international surveys, which are aimed at monitoring the behaviour and attitudes of managers, the rate of utilization and satisfaction of various management methods and tools. Successful implementation requires an understanding of their strengths and weaknesses, as well as the ability to creatively integrate the right tools in the right way.
\end{abstract}

Keywords: management, globalization, management trends, management tools

JEL Classification: $M 10 ; M 12 ; M 21$

\footnotetext{
*Corresponding author: andrea.cambalikova@euba.sk
} 


\section{Introduction}

Every organization operating in the current uncertain economic climate must know how to deal with change to survive. The pace of change has increased significantly in recent years and change has become part of the daily reality of businesses and organizations. In today's complex and competitive global business environment, organizations must adapt to changing environmental conditions and constant change to remain competitive and profitable. Severe competition is a reality. Market has changed, new players have entered and competiveness is higher. Also Slovak businesses must carefully monitor changes on market and react to demands of domestic and international markets [1]. To remain competitive, it is especially necessary to respond promptly to various stimulus, such as environmental turbulence, innovation, external as well as internal changes. Organizations, that are inactive to change, often run the risk of losing their competitive advantage and they are at high risk. Therefore, it is necessary for companies to monitor changes, evaluate them and respond adequately through the management apparatus. As a result of the changes, the requirements for business management are constantly increasing, which leads to the development of managerial theory and practice, which is enriched with new knowledge. Approaches that have worked in the past often do not meet the conditions created by the new modern society, which conditioned the emergence of new management methods and tools. It is the new management methods and tools that help organizations adapt to current market requirements and are a key factor in ensuring business efficiency, profitability and finally, competitiveness. The implementation of managerial trends is a complex process in which the managers themselves are largely involved. To introduce and use new methods and tools, managers must have the relevant knowledge, as well as the ability to select and implement the appropriate method in the best possible way.

Globalization and the processes of internationalization, development in the field of informatics and telecommunications, together with significant socio-economic changes, place enormous demands on the improvement of management. These are reflected in the search for new, more effective management methods and techniques and in the generalization of practical knowledge. Outdated methods, techniques and tools are being replaced by new ones that meet changing conditions and assumptions.

The surrounding world is subject to change that takes place in short periods of time, often from one day to the next, or from hour to hour. Companies are also affected by changes, which are generally so rapid, turbulent, and ground-breaking that they can barely cope with them and others are already heading towards them. One of the essential conditions for the effective operation of a company is to adapt to changing conditions and new market opportunities. Within the company, the managing authorities help to fulfil this condition, which monitors, evaluates individual changes, and seeks a way to respond to them appropriately. The success of the company is reflected in the quality of management, which also results in a constant increase in demands on management. The use of processes and activities that have been beneficial in the past becomes insufficient under the influence of the pace of development and it is desirable to ensure new trends for the successful implementation of the company. Applying new methods and procedures to the company can increase performance and improve its position in the competitive environment.

Consulting organization Bain \& Company has been monitoring the introduction of new methods and procedures into the company since 1993. The company monitors executives from around the world and finds out which management tools they use most often and how effectively these tools have worked in practice. Every year or two, they have conducted research to identify 25 of the most popular and pertinent management tools, the most current tool selection is shown in Table no.1 [2]. The persistence and power of ongoing digital transformation is evident in the results of our most recent Management Tools \& 
Trends survey, as managers embrace digital tools like advanced analytics and the internet of things. Advanced analytics create actionable ideas for delivering sustained value, measuring performance, and establishing competitive advantages [3]. Digital natives and established technology companies are turning new management and organizational concepts into operational realities, as they move away from hierarchical structures and embrace agile management, accelerating innovation and pushing power and responsibility to the front line. Digital transformation opens new possibilities to improve operating efficiency, develop more accurate and agile planning, heighten vendor awareness, and collaborate with business partners throughout the value chain [4]. So these three tools have been added as new into the last survey.

Table 1.25 of the most popular management tools.

\begin{tabular}{|l|l|}
\hline 1. Advanced Analytics & 14. Employee Engagement Systems \\
\hline 2. Agile Management & 15. Internet of Things \\
\hline 3. Balanced Scorecard & 16. Mergers and Acquisitions \\
\hline 4. Benchmarking & 17. Mission and Vision Statements \\
\hline 5. Business Process Reengineering & 18. Organizational Time Management \\
\hline 6. Change Management Programs & 19. Price Optimization Models \\
\hline 7. Complexity Reduction & 20. Scenario and Contingency Planning \\
\hline 8. Core Competencies & 21. Strategic Alliances \\
\hline 9. Customer Journey Analysis & 22. Strategic Planning \\
\hline 10. Customer Relationship Management & 23. Supply Chain Management \\
\hline 11. Customer Satisfaction Systems & 24. Total Quality Management \\
\hline 12. Customer Segmentation & 25. Zero-Based Budgeting \\
\hline 13. Digital Transformation & \\
\hline
\end{tabular}

To be included into the survey, a tool needs to be relevant to senior management, topical and measurable. The most current research of Bain \& Company, which was carried out in 2017 [5], was their 16th survey with 1268 managers participated in it. They have more than 14700 respondents from more than 70 countries of North America, Europe, Asia, Africa, the Middle East and Latin America. They systematically trace the effectiveness of management tools over the years, and as a part of their survey, they also ask executives for their opinions on a range of important business issues. As a result, they are able to track and report on changing management priorities [6]. The results of this managers interviewing we can consider as certain trends in the business environment. It is essential, that managers keep up with the times and follow current trends in the environment. The term trend represents a component of a long-term direction, or it is a tendency to change that lasts for a relatively longer time. The results of the survey shown in Table no. 2 [6] provide with top 10 management trends evaluated by managers worldwide. We can see the broad move to empower teams happening across industries, from small regional firms to major multinationals, and in both emerging and developed markets. Among managers, 4 out of 5 agreed with the idea, that today's business leaders must trust 
and empower people, not command and control them, only 5\% disagreed. Three quarters of respondents consider culture at least as important as strategy for their business success. The third trend, which was the most agreed by managers (67\%) was statement, that supply chain capabilities are increasingly vital to success in their industry.

Table 2. Top 10 management trends.

\begin{tabular}{|l|c|c|}
\hline Trends & Agree & Disagree \\
\hline $\begin{array}{l}\text { 1. Today's business leaders must trust and empower people, not } \\
\text { command, and control them }\end{array}$ & $79 \%$ & $5 \%$ \\
\hline 2. Culture is at least as important as strategy for business success & $75 \%$ & $8 \%$ \\
\hline $\begin{array}{l}\text { 3. Supply chain capabilities are increasingly vital to success in } \\
\text { our industry }\end{array}$ & $67 \%$ & $9 \%$ \\
\hline $\begin{array}{l}\text { 4. Digital disruptions and software solutions are rapidly changing } \\
\text { the rules of competition }\end{array}$ & $66 \%$ & $9 \%$ \\
\hline $\begin{array}{l}\text { 5. We are disciplined cost managers who focus our spending on } \\
\text { strategic priorities }\end{array}$ & $63 \%$ & $13 \%$ \\
\hline $\begin{array}{l}\text { 6. Customers are less loyal to brands than they used to be } \\
\text { 7. We could dramatically boost innovation, by collaborating with } \\
\text { outsider, even competitors }\end{array}$ & $61 \%$ & $15 \%$ \\
\hline $\begin{array}{l}\text { 8. Excessive complexity is raising our costs and hindering our } \\
\text { growth }\end{array}$ & $58 \%$ & $15 \%$ \\
\hline $\begin{array}{l}\text { 9. Bureaucracy and excessive levels of hierarchy are putting us at } \\
\text { a competitive disadvantage }\end{array}$ & $56 \%$ & $20 \%$ \\
\hline $\begin{array}{l}\text { 10. Effective mergers and acquisitions will be critical to success } \\
\text { in our industry }\end{array}$ & $56 \%$ & $19 \%$ \\
\hline
\end{tabular}

Topping the list of the 25 most popular management tools (see Table 1) is strategic planning, as the process of determining what a business should become and how it can best achieve that goal. Constantly, among the top ten list, this time strategic planning as a managerial tool ranks no. 1 based on global usage, with usage rate $48.3 \%$. As companies navigate this fourth industrial revolution, hoping to grow and thrive in a quickly changing environment, understanding how to be of value to customers only becomes more vital. It's understandable then, that customer relationship management (CRM), which focuses on understanding customers and responding quickly to their shifting desires, ranks no. 2 on the list, close behind strategic planning, with usage rate $48,1 \%$. Benchmarking as the third most used management tool has reached a level of usage $46 \%$.

When applying the individual tools, in addition to the usage, it was evaluated the respondents' satisfaction with the tools. Satisfaction was rated on a scale of 1 to 5, with a value of 5 indicating that they were very satisfied with the tool, and a value of 1 indicating, that they were very dissatisfied. Satisfaction rate with strategic planning was 4.03, CRM reached score 4.01, and benchmarking reached score 3.94 [6]. Usage and satisfaction rates are shown in Fig. no.1 and are demonstrated with the three most popular tools. 


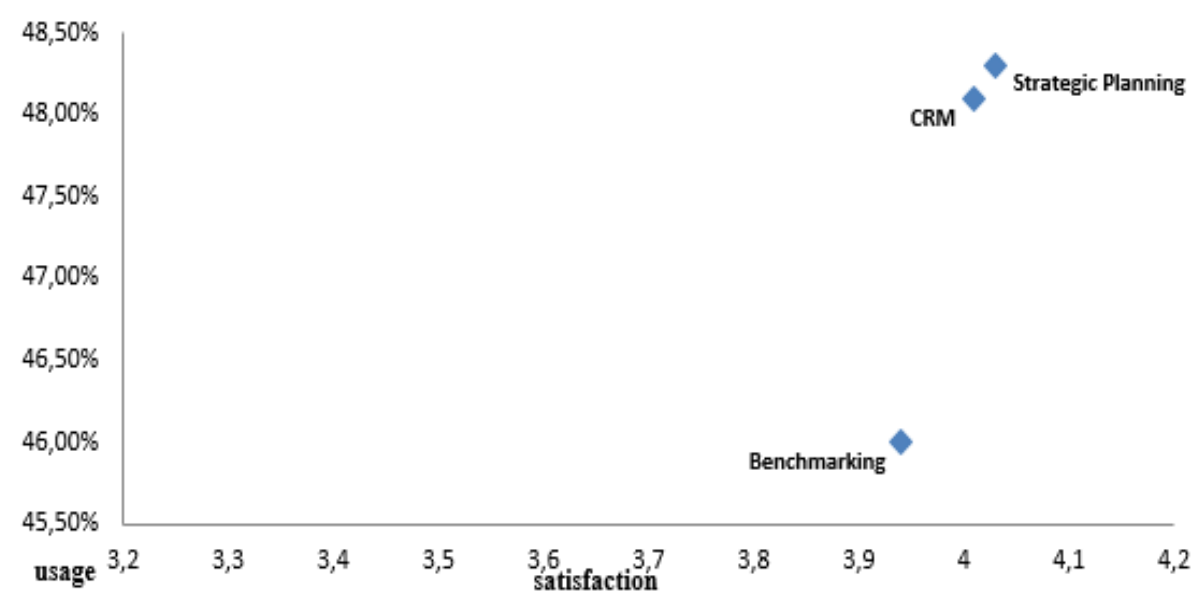

Fig. 1. Usage and satisfaction rates of top 3 tools worldwide.

Strategic planning is an organization's process of defining its strategy, or direction, and making decisions on allocating its resources to pursue this strategy. The leader tries by strategic or long-range planning to assist the company in establishing priorities and to better serve the needs of the membership [7]. Realized strategies, the actual pattern of decisions and actions over time, not only are an outcome of deliberate planning but also are influenced by emergent forces, that is, the decisions and actions arising within an organization that contribute to the pattern but that are not anticipated in the plan [8].

Customer relationship management refers to building one-to-one relationships with customers, that can drive value for the firm. This manuscript discusses proven CRM strategies that companies can use as means of effective customer management. In the current period can be observed more intensive use of information technologies for collecting and storing information about clients. This trend is also reflected in the use of innovative approaches to relationship marketing, which gave rise to new types of customer relationship management. These are primarily electronic (eCRM) and social (SCRM) [9]. Social media technologies create environments that can engage customers in collaborative conversations and enhance customer relationships [10]. Today, many companies are using social media conversations to capture more personal and nuanced information about their customers. Social media can provide detailed information on customers' habits, feedback, and needs, and these details can now be stored in the CRM systems used by sales professionals [11]. Understanding the firms' key customers and its competitors would aid managers in responding to the changing environment and the restructuring of the organizational strategy accordingly. It would also enable managers to formulate and change the strategic approach toward the portfolio of customers that fits the objective of the organization [12].

Benchmarking is the process of comparing one's business processes and performance metrics to industry bests and best practices from other companies. Dimensions typically measured are quality, time, and cost.

The innovative environment will continue to be subject to the changes brought about by the phenomenon of digitization. Certainly fundamental, revolutionary and indepth changes are waiting for us and each enterprise will have to accept and implement new, modern information technologies that will be related to the effective change of business under the influence of Industry 4.0 [13]. This research has found that revolutionary technologies bring fundamental changes to society and the business environment. Changes caused by technological progress affect competition, 
participate in variation in the way companies work, manage, and organize. The neverending digital transformation converts organizational and management concepts into operational reality, within which hierarchical structures are less and less applied and new trends from the sphere of management dominate.

\section{Methods}

The subject of the paper has been processed using the analysis of secondary data, the available foreign scientific literature related to the research issue, which is listed in the references. We have used a wide range of articles from scientific journals related to the processing issue and electronic resources. We have also worked with the results of the consulting companies' surveys, mainly with the results of an international survey conducted by Bain \& Company entitled "Management Tools \& Trends", which served us for the needs of comparison of the state in modern trends in management in the world and in the Slovakia. The object of the survey was represented by a sufficiently large and representative sample of enterprises operating in Slovakia for the purpose of realization a primary survey. The questionnaire survey was aimed at determining the extent of application of individual modern methods and tools used during realization of managerial functions, in different types of organizations operating in different sectors. When processing the research topic, primary data were obtained by the realization of the survey using standardized questionnaires and by the realization of a qualitative survey through interviews with the executives. Respondents, in view of the questionnaire focus, were mainly executives of companies, managing directors and managers at the least intermediate level of management. The survey was conducted in the year 2017 with a total sample of 203 enterprises. From the methodological procedures, we used individual general methods in the paper, mainly the method of analysis and synthesis, the method of induction and deduction, as well as the description. From the specific theoretical methods, we applied the method of comparison to achieve a clearer processing of diverse data and information, we also used the method of graphical display, which allowed us to organize the data into tables and graphs.

\section{Results and Discussions}

In our research [14], we have looked into the level of awareness and use of the selected thirteen modern trends in management, in which areas of management they are used, and how satisfied are managers with them. To clarify, these were the 13 tools: advanced analytics, balanced scorecard, benchmarking, complexity reduction, CRM, digital transformation, employee engagement survey, change management, satisfaction and loyalty management, social media programs, strategic planning, talent management, time management. Respondents from the sample have made the greatest use of the strategic planning management tool, 145 of them, which is $71 \%$. Only 27 respondents (13\%) did not know the given tool. Only slightly fewer companies use customer relationship management, namely 142 companies (70\%), while CRM did not know 29 companies from the sample $(14 \%)$. The third most widely used management tool was time management, which was used by 122 companies (60\%). 32 companies (18\%) identified the tool as unknown. The group of tools and methods used by most companies in their management practice also includes benchmarking, where the usage rate of this method reached the level of 55\% (112 companies). The first two most used tools were the same compared to the worldwide survey. In our result time management was widely used than benchmarking. Based on our research, respondents [14] were the most satisfied with the strategic planning tool, which 
was evaluated on average 4 points (rather satisfied) and at the same time this tool is also the most widely used. A high level of satisfaction is also recorded with the CRM concept (3.9) and benchmarking (3.8). Within the group of selected tools, respondents reported the lowest satisfaction rates with complexity reduction tool (3.3), balanced scorecard (3.4), and advanced analytics tool (3.5). In general, it can be said, if the satisfaction with a given tool is higher, then the rate of its use is higher, and vice versa. The rates achieved in assessing satisfaction were very similar with an international survey.

If companies have applied one of the modern management tools, we have found out more from them in which areas they use it in their management. They had several options to choose from: planning, organizing, leadership, human resources (within development, motivation, and employee's assessment), control, decision-making, communication, implementation, working with information and in relation to customers or suppliers. Strategic planning is most often used by companies in planning, which was declared by up to $64 \%$ of them. When organizing, $25 \%$ of companies apply strategic planning and $22 \%$ when making decisions. Customer relationship management is the method most often used in companies in relation to customers, and this option was chosen by up to $58 \%$ of companies. Businesses also often reported using CRM in communication (26\%) and in working with the information (12\%). Benchmarking is the tool most used by businesses in planning (29\%), decision-making (18\%) and organizing $(17 \%)$. Of the sample, $12 \%$ of companies use benchmarking also within the control and in relation to their customers or suppliers.

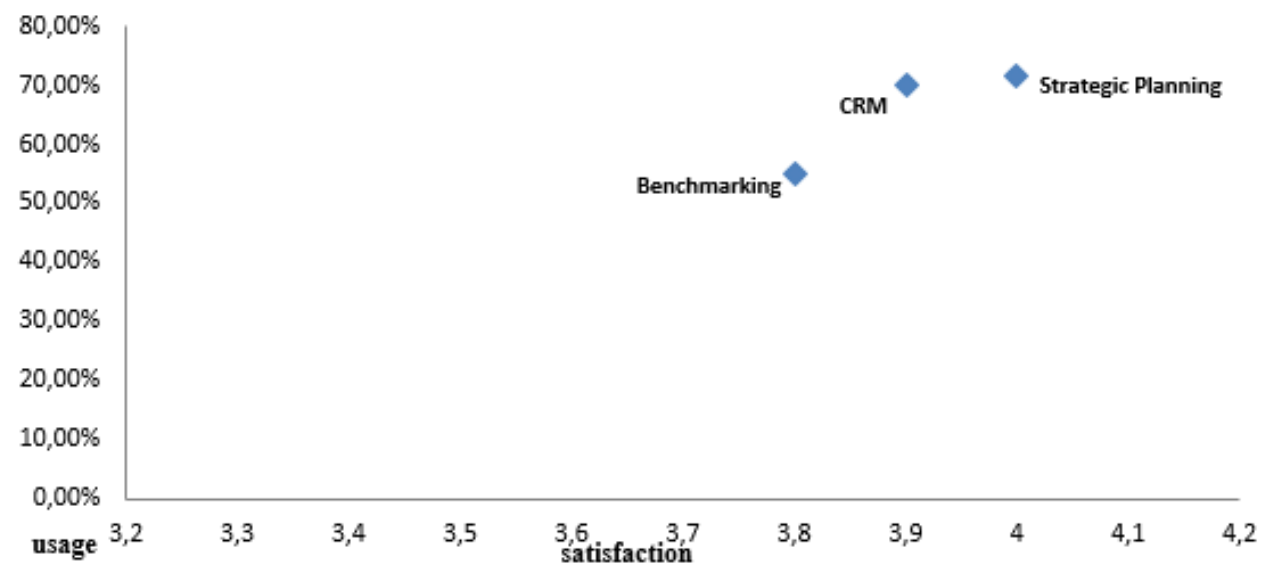

Fig. 1. Usage and satisfaction rates of top 3 tools in Slovakia.

Constant changes in the business environment caused by globalization, digitization and dynamic development of technology can be monitored on a daily basis, both in the domestic and foreign spheres. In order to succeed in an environment of market economy, business must seek new opportunities offered by market and thus increase its innovation activity that leads to development of innovation potential [15]. Innovation as a mindset addresses the internalization of innovation by individual members of the organization and advancement of a supportive culture throughout the organization [16]. The unstable environment has created the main impulse for taking measures and ways that will ensure the company's management to respond effectively, reduce risk and benefit from the current situation. For effective management of the company, it is necessary to give up the usual management methods and tools in certain areas and to create space for the penetration and application of new possibilities in the form of modern methods and tools. It is the use of new methods and tools in management that can bring the company success and increase competitiveness. Those companies that are considered flexible and agile, are able to adapt 
to the changing environment, and at the same time see the potential to improve their business activities, are well placed to apply modern trends in management. As the COVID19 crisis continues to impact businesses in the next few years, economic, societal, and technological changes will become unavoidable for survival [17].

As companies strive for growth and innovation in today's rapid era of technological change, as a part of discussion, we offer the following suggestions to help managers and businesses get the most out of the established tools they choose:

- Gain information - each tool has strengths and weaknesses that need to be considered, as well as the nature of the tool and what it is used for. The usefulness of tools can change over the life of a business. To succeed, businesses must fully understand the effects of each tool and then combine the right tools in the right way at the right time. Managers should follow research in the field, discuss with other users of the tools, and do not use the naive hyperbola and simplified solutions.

- Persistence - a strategy of persistence in the implementation of the tool, not just a "fashion" issue, but a realistic strategic direction, a rational approach to the selection and implementation of tools, tools as a helper, not a solution for everything.

- Adaptation of tools to processes - adaptation of tools to business processes and systems (business model) - not vice versa.

Making more effort will allow companies to achieve better values of satisfaction than limited effort, it is better not just do it "halfway". If management can participate only to a limited extent, it may be best to avoid using some tools. If the company does not have sufficient qualified and competent own resources, they can hire an external consultant to provide the solution, assuming that the person has a good knowledge of a tool or method, as well as the information about the market and working procedures.

The general use of management tools rises and falls in cycles and often reflecting the macroeconomic environment as well as competitive dynamic. The effectiveness and efficiency of the manager's influence on the development of the company is conditioned by his actions, which accompanies him in solving problems appearing on the way to development and especially whether he can properly use individual methods and techniques based on the organization management theory and are verified in practice. It is also necessary for the manager to constantly progress over time and follow current trends in methods and management techniques.

This paper is a partial output of the project of young teachers, researchers and doctoral students no. I20-103-00 "Evaluation of innovation potential in the context of new management trends on the basis of proposed determinants in the automotive industry" in the range of $50 \%$, and project VEGA Ministry of Education SR no. 1/0017/20 "Changes in the application of managerial functions in the context of the fourth industrial revolution and adaptation processes of companies in Slovakia" in the range of $50 \%$.

\section{References}

1. Porubanová, K., Richnák, P. (2017). Usability of Intangible Assets in the Terms of Manufacturing Companies. AD ALTA: journal of interdisciplinary research, 7(2), 177180.

2. Rigby, D. K. (2017). Management tools 2017. An executive's guide. https://media.bain.com/Images/BAIN_BOOK_Management_Tools_2017.pdf

3. Wamba, S. F., Gunasekaran, A., Akter, S., Ren, J. F., Dubey, R., Childe, S. J. (2017) Big data analytics and firm performance: Effects of dynamic capabilities. Journal of Business Research 70, 356-365 
4. Sganzerla, C., Seixas, C., Conti, A. (2016). Disruptive innovation in digital mining. Procedia Engineering 138, 64-71.

5. Rigby, D. K. , Bilodeau, B. (2018, April 2). A history of Bain's Management Tools \& Trends survey. https:/www.bain.com/insights/management-tools-about-the-survey/

6. Rigby, D. K. , Bilodeau, B. (2018, April 5). Management Tools \& Trends. https://www.bain.com/insights/management-tools-and-trends-2017/

7. Bouhali, R., Mekdad, Y., Lebsir, H., Ferhka, L. (2015). Leader Roles for Innovation: Strategic Thinking and Planning. Procedia Social and Behavioral Sciences 181, 72-78.

8. Wolf, C., Floyd, S. W. (2017). Strategic planning research: Toward a theory-driven agenda. Journal of Management, 43(6), 1754-1788.

9. Kubina, M., Lendel, V. (2015). Successful Application of Social CRM in The Company. Procedia Economics and Finance 23, 1190-1194.

10. Kim, H. G., Wang, Z. (2019). Defining and measuring social customer-relationship management (CRM) capabilities. Journal of Marketing Analytics, 7(1), 40-50.

11. Agnihotri, R., Trainor, K. J., Itani, O. S., \& Rodriguez, M. (2017). Examining the role of sales-based CRM technology and social media use on post-sale service behaviors in India. Journal of Business Research, 81, 144-154.

12. Thakur, R., Workman, L. (2016). Customer portfolio management (CPM) for improved customer relationship management (CRM): Are your customers platinum, gold, silver, or bronze?. Journal of Business Research, 69(10), 4095-4102.

13. Romanová, A., Richnák, P., Porubanová, K., Bolek, V. (2019). Application of Modern Information Technology in Innovation of Business Logistic Processes. Ad Alta: Journal Of Interdisciplinary Research, 9(1), 245-248.

14. Szabo, L., Čambalíková, A. (2017). Modern trends in management and their application by enterprises in Slovakia. Brno: Tribun EU.

15. Gubová, K., Richnák, P. (2016). Innovative activity of Slovakia in comparison with EU countries. Ad Alta: Journal Of Interdisciplinary Research, 6(1), 18-21.

16. Kahn, K. B. (2018). Understanding innovation. Business Horizons, 61(3), 453-460.

17. Verma, S., Gustafsson, A. (2020). Investigating the emerging COVID-19 research trends in the field of business and management: A bibliometric analysis approach. Journal of Business Research, 118, 253-261. 